\title{
PERSEPSI DAN TINGKAT KEPUASAN TARUNA TERHADAP PELAYANAN PERPUSTAKAAN \\ (Studi Kasus di STP Jurusan Penyuluhan Perikanan Bogor)
}

\author{
Oleh: \\ Abdul Hanan, Nayu Nurmalia \\ Dosen Jurusan Penyuluhan Perikanan Sekolah Tinggi Perikanan
}

\begin{abstract}
ABSTRAK
Dalam pemanfaatan pelayanan Perpustakaan diperoleh data bahwa taruna berkunjung ke perpustakaan kurang dari rata-rata 2 kali dalam sebulan sebanyak $27,8 \%$, berkunjung sebanyak 3 sampai 4 kali per bulan sebanyak 45,8\% dan yang berkunjung lebih dari 5 kali sebanyak 26,4\%. Hasil analisis tingkat Indek Kepuasan Taruna (IKP) terhadap 14 unsur pelayanan di unit Perpustakaan. Hasil analisis terhadap 14 unsur pelayanan perpustakaan terhadap taruna sebagai pengguna bahwa hanya satu unsur yang meperoleh indek kepuasaan dengan katagori sangat baik, 2 unsur pelayanan indek kepuasasan dengan katagori kurang baik, dan 11 unsur indek kepusan pada katagori baik. Untuk mengetahui mutu pelayanan dan kinerja unit perpustakaan maka dilakukan analisis dengan rumus $\mathrm{U}^{\mathrm{n}} \times 0,0071$ dalam hal ini Un adalah nilai rata-rata per unsur pelayanan, dan 0,071 adalah nilai bobot rata-rata tertimbang.

Hasil analisis memperlihatkan bahwa nilai kepuasan tertinggi diperoleh pada unsur 5 (U5) yaitu tanggung jawab petugas pelayanan, sedangkan nilai kepuasan pelayanan yang paling rendah pada unsur 10 (U10) yaitu kelengkapan buku yang dibutuhkan.

Key word: Persepsi, Pelayanan, Indek kepuasan

\section{PENDAHULUAN}

\section{Latar Belakang}

Pelayanan publik bertalian dengan ketersediaan dan cara menyampaikan berbagai layanan dalam bentuk barang dan jasa publik yang telah ditentukan, dijanjikan atau diwajibkan kepada penyelenggara pelayanan. Ketersediaan berhubungan dengan jumlah atau kecukupan atas barang dan jasa publik yang seharusnya menjadi tanggung jawab penyedia layanan. Sedangkan cara menyampaikan layanan publik adalah

metoda, teknik atau sistem yang digunakan untuk menjamin pemenuhan kebutuhan pengguna layanan publik.

Jurusan Penyuluhan Perikanan Bogor Sekolah Tinggi Perikanan, merupakan lembaga pendidikan kedinasan yang dibiayai oleh pemerintah dalam hal ini Kementrian Kelautan dan Perikanan merupakan institusi yang memberikan pelayanan kepada taruna sebagai sasaran didik. Unit Perpustakaan merupakan unit yang sangat penting bagi taruna dalam rangka menunjang proses belajar mengajar, dan sebagai sumber ilmu dengan keberadaan buku-buku
\end{abstract}


yang dibutuhkan taruna dalam rangka memperkaya proses belajar mengajar di kelas.

\section{Permasalahan}

Pelayanan yang diberikan unit perpustakaan dan unit kesehatan di Jurusan penyuluhan Perikanan Bogor merupakan fenomena yang menarik, dikarenakan pada unit pelayanan tersebut sarana prasarana maupun pembiayaan seluruhnya disediakan oleh intansi, sehingga taruna tinggal memanfaatkan fasilitas pelayanan tersebut. Namun demikian seringkali faktor internal petugas pelayanan serta faktor eksternal dari petugas pelayanan ikut mempengaruhi tingkat pelayanan. Gambar 1.

KERANGKA PIKIR DAN HIPOTESIS

\begin{tabular}{|l|l|}
\hline \multicolumn{1}{|c|}{ UNSUR PELAYANAN } & \\
\hline$>$ Prosedur & $(\mathrm{X} 1)$ \\
\hline$>$ Persyaratan & $(\mathrm{X} 2)$ \\
\hline \multicolumn{1}{|c|}{ Kejelasan petugas } & $(\mathrm{X} 3)$ \\
\hline$>$ Kedisiplinan & $(\mathrm{X} 4)$ \\
\hline$>$ Tanggung jawab & $(\mathrm{X} 5)$ \\
\hline$>$ Kompetensi & $(\mathrm{X} 6)$ \\
\hline$>$ Kecepatan pelayanan & $(\mathrm{X} 7)$ \\
\hline$>$ Keadilan pelayanan & $(\mathrm{X} 8)$ \\
\hline$>$ Kesopanan dan keramahan & $(\mathrm{X} 9)$ \\
\hline$>$ Kelengkapan buku & $(\mathrm{X} 10)$ \\
\hline$>$ Kesesuaian buku & $(\mathrm{X} 11)$ \\
\hline$>$ Kepastian jawal tugas & $(\mathrm{X} 12)$ \\
\hline$>$ Kenyamanan & $(\mathrm{X} 13)$ \\
\hline$>$ Keamanan & $(\mathrm{X} 14)$ \\
\hline
\end{tabular}

Gambar 1. Kerangka Pikir Penelitian

\section{Hipotesis Penelitian}

1. Terdapat beberapa unsur pelayanan yang mempengaruhi tingkat kepuasan taruna

2. Semua unsur pelayanan mempengaruhi tingkat kepuasan taruna

\section{METODE PENELITIAN}

Penelitian dilakukan di Kampus Sekolah Tinggi Perikanan Jurusan Penyuluhan Perikanan Bogor. Penelitan dilakukan selama 8 minggu di Bulan Maret sampai April 2013. Sampel pada penelitian ini adalah taruna tingkat II, III dan IV masing-masing sebanyak 70 responden. Data yang dikumpulkan 
terdiri dari data primer dan data sekunder. Data primer dikumpulkan dengan wawancara kepada taruna menggunakan daftar pertanyaan (kuisioner) yang telah disiapkan, dan dilakukan juga wawancara mendalam (indepth interview) dengan petugas yang meberikan pelayanan di perpustakaan dan unit layanan kesehatan.

\section{ANALISA DATA}

Analisa data dilakukan secara deskriftif, analisa kualitatif dilakukan untuk semua tujuan penelitian, analisa kuantitatif dilakukan untuk menguji hipotesis yang diajukan.

Karakteristik internal dan karakteristik eksternal diukur dengan menggunakan distribusi frekuensi dan nilai tengah. Untuk mengetahui hubungan antar peubah dilakukan analisis hubungan dengan koefisien korelasi Spearman, sebagai uji korelasi bagi data non parametrik.
Analisa Indeks Kepuasan Taruna (IKT) dengan menggunakn nilai rata-rata tertimbang masing-masing unsur pelayanan. Dalam perhitungan IKT unsur pelayanan yang dikaji setiap unsur pelayanan memeiliki penimbang yang sama dengan menggunakan rumus:

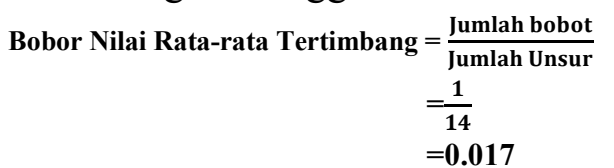

Sedangkan untuk memperoleh nilai IKT unit pelayanan digunakan pendekatan nilai rata-rata tertimbang dengan rumus sebagai berikut:

$$
\begin{aligned}
& \frac{\text { Total dari nilai persepsi per unsur }}{\text { Total Unsur yang Terisi }} \\
& \times \text { Nilai Tertimbang }
\end{aligned}
$$

Nilai Persepsi Interval IKT, Nilai Interval Konversi, Mutu Pelayanan dan Kinerja Unit Pelayanan

Tabel 1. (Kepmenpan No. 25/M.PAN/2/2004)

\begin{tabular}{|c|c|c|c|c|}
\hline $\begin{array}{c}\text { Nilai } \\
\text { Persepsi }\end{array}$ & Nilai Interval & $\begin{array}{c}\text { Nilai Interval } \\
\text { Konversi }\end{array}$ & Mutu Pelayanan & $\begin{array}{c}\text { Kinerja Unit } \\
\text { Pelayanan1 }\end{array}$ \\
\hline 1 & $1,00-1,75$ & $25-43,75$ & $\mathrm{D}$ & Tidak baik \\
\hline 2 & $1,76-2,50$ & $43,76-62,50$ & $\mathrm{C}$ & Kurang baik \\
\hline 3 & $2,51-3,25$ & $62,51-81,25$ & $\mathrm{~B}$ & Baik \\
\hline 4 & $3,26-4,00$ & $81,26-100$ & $\mathrm{~A}$ & Sangat baik \\
\hline
\end{tabular}

\section{HASIL DAN PEMBAHASAN}

Sekolah Tinggi Perikanan adalah sekolah kedinasan yaitu para taruna maupun taruni mengikuti pendidikan selama 4 tahun harus tinggal di asrama yang difasilitasi oleh Sekolah. Disamping itu sekolah juga menyediakan pelayanan berupa fasilitas untuk kesehatan yang dinamakan Pos
Kesehatan taruna, dan fasilitas perpustakaan dan pelayanan lainnya. Perpustakaan merupakan unit yang sangat penting dalam proses belajar mengajar. Kenyamanan dalam pengelolaan unit perpustakaan tersebut akan mempengaruhi motivasi masyarakat pengguna untuk mau memanfaatkan unit perpustakaan tersebut sebagai sumber ilmu 
pengetahuan. Pada unit pelayanan perpustakaan yang ada di Jurusan Penyuluhan Perikanan Bogor memfasiltasi kebutuhan taruna dari pukul 08.00 WIB sampai pukul 16.00 WIB dan menyediakan pelayanan sampai pukul 21.00 WIB 2 (dua) hari dalam satu minggu.

\section{Karakteristik Responden}

Sebaran karakteriktik internal responden penelitian yaitu jenis kelamin, asal daerah, tingkat pendidikan, pekerjaan orang tua, besaran uang saku per bulan, rata-rata berkunjung ke perpustakaan, dan ke pos kesehatan, seperti pada Tabel 2 .

Tabel 2. Sebaran Karakteriktik Internal

\begin{tabular}{|c|c|c|c|c|c|}
\hline No & Karakteristik & Katagori & $\begin{array}{c}\text { Persentase } \\
(\mathrm{N}=70)\end{array}$ & Interval & $\begin{array}{l}\text { Rata- } \\
\text { Rata }\end{array}$ \\
\hline 1 & Jenis kelamin & $\begin{array}{l}\text { Laki-laki } \\
\text { Perempuan }\end{array}$ & $\begin{array}{l}51 \\
49\end{array}$ & - & - \\
\hline 2 & Asal Daerah & $\begin{array}{l}\text { Pulau jawa dan bali } \\
\text { Pulau Sumatera } \\
\text { Pulau Kalimantan } \\
\text { Indonesia Bagian Timur }\end{array}$ & $\begin{array}{l}37 \\
23 \\
15 \\
25\end{array}$ & & \\
\hline 3 & Tingkat pendidikan & $\begin{array}{l}\text { TK. II } \\
\text { TK III } \\
\text { TK IV }\end{array}$ & $\begin{array}{l}40 \\
40 \\
20\end{array}$ & & \\
\hline 4 & Pekerjaan Orang Tua & $\begin{array}{l}\text { PNS } \\
\text { Swasata } \\
\text { Wiraswasta } \\
\text { Pelaku Utrama } \\
\text { Tidak berkerja }\end{array}$ & $\begin{array}{c}37(51,4) \\
4(5,6) \\
8(11,2) \\
20(27,8) \\
3(4,2)\end{array}$ & & \\
\hline 5 & $\begin{array}{l}\text { Besar Uang saku per } \\
\text { bulan }\end{array}$ & $\begin{array}{l}<\operatorname{Rp} 200.000 \\
\operatorname{Rp} 250.00-R p 350.000 \\
\operatorname{Rp} 400.000-500.000 \\
>500.000\end{array}$ & $\begin{array}{l}10(13,9) \\
23(31,9) \\
23(31,9) \\
16(12,3)\end{array}$ & $\begin{array}{c}200.000- \\
900.000\end{array}$ & $500.000,-$ \\
\hline 6 & $\begin{array}{l}\text { Rata-rata Berkunjung Ke } \\
\text { Perpustaan }\end{array}$ & $\begin{array}{l}<2 \text { kali/bulan } \\
3-4 \text { kali/bulan } \\
>5 \text { kali/bulan }\end{array}$ & $\begin{array}{l}20(27,8) \\
33(45,8) \\
19(26,4)\end{array}$ & $1-3$ & 2 \\
\hline
\end{tabular}

Pada Tabel 2 memperlihatkan bahwa jenis kelamin responden 51\% laki-laki dan $49 \%$ perempuan. Asal daerah responden dari Pulau Jawa 32\%, Pulau Sumatera 23\%, Pulau Kalimantan $15 \%$ dan Dari Pulau Indonesia Bagian Timur 25\%. Tingkat pendidikan responden sebanyak 40\% Taruna Perdana (TK II), sebanyak 40\% Taruna Madya (TK III) dan sebanyak 20\% Taruna Utama (TK IV). Pekerjaan orang tua taruna sebanyak $51,4 \%$ sebagai Pegawai negeri Sipil, sebanyak 5,6\% pekerjaaan swasta, sebanyak 11,2\% pekerjaan wiraswasta, pekerjaan sebagai pelaku utama perikanan sebanyak 27,8\% dan tidak berkerja sebanyak 4,5\%. Setaiap bulannya para orang tua taruna mengirimkan uang saku untuk biaya keperluan pribadi (sabun, buku, jajan, komunikasi) diperoleh data sebagai berikut: uang saku yang diterima taruna kisasaran paling tinggi Rp 200.000,- per bulan diterima oleh sebanyak 13,9\% taruna. Uang saku yang diterima taruna dengan kisaran Rp 200.000,- sampai Rp.300.000,- per bulan diterima oleh sebanyak 13,9\% taruna, uang kiriman 
orang tua taruna kisaran $\mathrm{Rp} 400.000$,sampai Rp 500.000,- per bulan diterima oleh sebanyak 31,9\% taruna, dan uang saku kiriman orang tua taruna dengan kisaran lebih dari $\mathrm{Rp} 500.000$,- per bulan diterima oleh 12,3\% taruna. Dalam pemanfaatan pelayanan Perpustakaan diperoleh data bahwa taruna berkunjung ke perpustakaan kurang dari rata-rata 2 kali dalam sebulan sebanyak $27,8 \%$, berkunjung sebanyak 3 sampai 4 kali per bulan sebanyak $45,8 \%$ dan yang berkunjung lebih dari 5 kali sebanyak $26,4 \%$. Hasil analisis tingkat Indek Kepuasan Taruna (IKP) terhadap 14 unsur pelayanan di unit Perpustakaan seperti pada Tabel 3.

Tabel 3. Hasil Pengolahan Data Indek Kepuasan Taruna Pada Unit Perpustakaa

\begin{tabular}{|l|l|c|c|c|}
\hline NO & \multicolumn{1}{|c|}{ UNSUR PELAYANAN } & KODE & INDEK KEPUASAN & KRITERIA \\
\hline 1 & Prosedur Pelayanan & $\mathrm{U} 1$ & 2,808 & Baik \\
\hline 2 & Persyaratan Pelayanan & $\mathrm{U} 2$ & 2,663 & Baik \\
\hline 3 & Kejelasan Petugas Pelayanan & $\mathrm{U} 3$ & 2,833 & Baik \\
\hline 4 & Kedisiplinan Petugas Pelayanan & $\mathrm{U} 4$ & 3,014 & Baik \\
\hline 5 & Tanggung Jawab Petugas Pelayanan & $\mathrm{U} 5$ & 3,458 & Sangat baik \\
\hline 6 & Kemampuan Petugas Pelayanan & $\mathrm{U} 6$ & 3,00 & Baik \\
\hline 7 & Kecepatan Pelayanan & $\mathrm{U} 7$ & 2,778 & Baik \\
\hline 8 & Keadilan mendapatkan pelayanan & $\mathrm{U} 8$ & 3,042 & Baik \\
\hline 9 & Kesopanan dan Keramahan Petugas & $\mathrm{U} 9$ & 2,917 & Kurang Baik \\
\hline 10 & Kelengkapan buku yang dibutuhkan & $\mathrm{U} 10$ & 2,264 & Baik \\
\hline 11 & Kesesuaian Buku yang dibutuhkan & $\mathrm{U} 11$ & 2,333 & Baik \\
\hline 12 & Kepastian jadwal pelayanan & $\mathrm{U} 12$ & 2,764 & \\
\hline 13 & Kenyamaman Lingkungan & $\mathrm{U} 13$ & 3,162 & \\
\hline 14 & Keamanan Pelayanan & $\mathrm{U} 14$ & 3,028 & \\
\hline $\begin{array}{l}\text { Kriteria: } \\
1,00-1,75=\text { tidak baik }\end{array}$ & & & \\
$1,76-2,5=$ kurang baik & & & \\
$2,51-3,25=$ baik & & & \\
$3,25-4,00=$ sangat baik & & &
\end{tabular}

Pada Tabel 3 memperlihatkan bawa berdasarkan hasil analisis terhadap 14 unsur pelayanan perpustakaan terhadap taruna sebagai pengguna bahwa hanya satu unsur yang memperoleh indek kepuasaan dengan katagori sangat baik, 2 unsur pelayanan indek kepuasasan dengan katagori kurang baik, dan 11 unsur indek kepuasan pada katagori baik. Adapun penjelasan ke 14 unsur tersebut yaitu: 1) Prosedur pelayanan, yaitu kemudahan tahapan pelayanan yang diberikan kepada taruna dalam hal alur pelayanan memperoleh indek kepuasan taruna 2,808 menunjukkan katagori baik. Hal tersebut menunjukkan bahwa petugas dan aturan yang diterapkan oleh perpustakaan tidak rumit dan berbelit-belit. 2) Persyaratan pelayanan dalam hal ini persyaratan teknis dan administratif yang diperlukan untuk mendapatkan pelayanan diperpustakaan kepada taruna memperoleh indek kepuasan sebesar 2,661 pada katagori baik. 3) Kejelasan petugas pelayanan, dalam hal ini keberadaan dan kepastian petugas yang memberikan pelayanan (nama, jabatan dan kewenangan) memperoleh indek kepuasan taruna sebesar 2.833 pada katagori baik. 4) Kedisiplinan petugas pelayanan, yaitu kesungguhan petugas 
dalam memberikan pelayanan terutama terhadap konsistensi waktu kerja sesuai ketentuan yang berlaku dinilai oleh taruna dengan indek kepuasan sebsar 3.014 katagori baik. 5) Tanggung jawab petugas pelayanan yaitu kejelasan wewenang dan tanggung jawab memberikan pelayanan kepada taruna yang memanfaatkan unit perpustakaan di nilai oleh taruna dan memperoleh indek kepuasan 3,458 dengan katagori sangat baik. 6) Kemampuan petugas, yaitu tingkat keahlian dan keterampilan yang dimiliki petugas perpustakaan dalam menyelesaikan/ memberikan pelayanan terhadap taruna memperoleh indek kepuasan sebsar 3,00 dengan katagori baik. 7) Kecepatan pelayanan, yaitu target waktu pelayanan terhadap taruna yang meminjam buku-buku dapat diselesaikan dalam waktu yang telah ditentukan, dinilai oleh taruna dengan indek kepuasan sebesar 2,778 dengan katagori baik. 8) Keadilan mendapatkan pelayanan, yaitu pelaksanaan pelayanan tidak membedakan tingkatan kelas taruna dan tidak membedan gender, dinilai taruna dengan indek kepuasan sebesar 3.042 dengan katagori baik. 9) Kesopanan dan Keramahan petugas, yaitu sikap dan perilaku petugas dalam memberikan pelayanan kepada taruna secara sopan dan ramah serta saling menghargai dan menghormati meperoleh nilai indek kepuasan sebsar 2,917 dengan katagori baik. 10) Kelengkapan buku yang dibutuhkan, yaitu ketersediaan buku-buku baik jumlah mauoun kualitas yang berkaitan dengan ilmu sosial penyuluhan dan perikanan memperoleh indek kepuasan 2,264 dengan katagori kurang baik. Artinya buku yang tersedia di perpustakaan sesuai dengan yang dibutuhkan taruna tidak mencukup bahkan belum ada. 11) Kesesuaian buku yang dibutuhkan, yaitu keberadaan buku-buku yang dibutuhkan sesuai dengan mata kuliah maupun untuk penyelesaian tugas dalam hal ini mendpat indek kepuasan taruna kurang baik dengan skor 2,333. 12) Kepastian jadwal pelayanan, yaitu pelaksanaan waktu pelayanan sesuai dengan aturan yang telah didtentukan mendapat skor nilai kepuasan sebesar 2,764 dengan katagori baik. 13) Kenyamanan lingkungan, yaitu kondisi sarana dan prasarana perpustakaan yang bersih, rapi, dan teratur sehingga dapat memberikan rasa nyaman ketika taruna berada dalam ruangan perpustakaan. Unsur tersebut memperoleh indek kepuasan sebsar 3,162 dengan katagori baik. 14) Keamanan pelayanan, yaitu terjaminnya tingkat keamanan lingkungan unit perpustakaan ataupun sarana yang digunakan, sehingga taruna merasa tenang ketika berada di dalam perpustakaan dan terhindar dari resikoresiko yang terjadi. Unsur ini memperoleh indek kepuasan sebesar 3,028 dengan katagori baik.

Untuk mengetahui mutu pelayanan dan kinerja unit perpustakaan maka dilakukan analisis dengan rumus $\mathrm{U}^{\mathrm{n}} \mathrm{x}$ 0,0071 dalam hal ini Un adalah nilai rata-rata per unsur pelayanan, dan 0,071 adalah nilai bobot rata-rata tertimbang. 


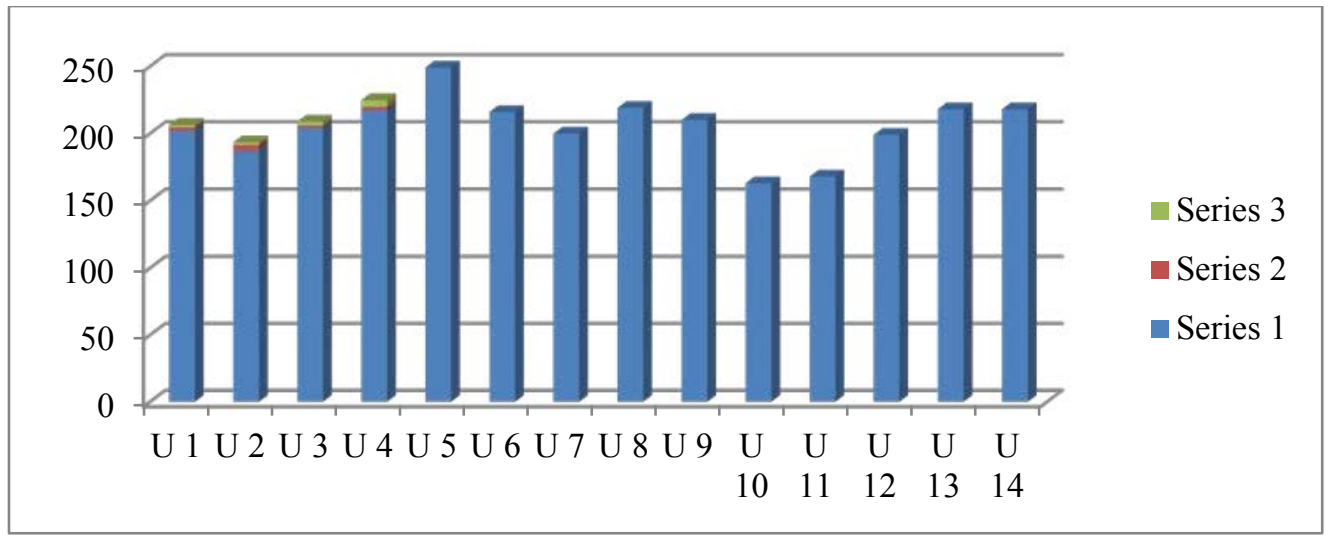

\section{Gambar 1. Perbandingan Indek Kepuasan Taruna Pada Pelayanan Unit Perpustakaan}

Pada grafik memperlihatkan bahwa nilai kepuasan tertinggi diperoleh pada unsur 5 (U5) yaitu tanggung jawab petugas pelayanan, sedangkan nilai kepuasn pelayanan yang paling rendah pada unsur 10 (U10) yaitu kelengkapan buku yang dibutuhkan.
Untuk mengtehui nilai indek pelayanan berupa mutu pelayanan dan kinerja dari unit perpustakaan Sekolah Tinggi Perikanan Jurusan Penyuluhan Perikanan Bogor dilakukan analisis dengan rumus

$$
\mathrm{U}^{\mathrm{n}} \times 0,071
$$

Ket: Un = Nilai rata-rata per unsur pelayanan

$0,071=$ Nilai bobot rata-rata tertimbang

$$
\begin{aligned}
& (2,808 \times 0,071)+(2,634 \times 0,071)+(2,833 \times 0,071)+(3,014 \times 0,071)+ \\
& (3,458 \times 0,071)+(3,00 \times 0,071)+(2,778 \times 0,071)+(3,04 \times 0,071)+ \\
& (2,997 \times 0,071)+(2,264 \times 0,071)+(2,333 \times 0,071)+(2,764 \times 0,071)+(3, \\
& 167 \times 0,071)+(3,028 \times 0,071)=\text { nilai indek adalah } 2,843
\end{aligned}
$$

Berdasarkan hasil perhitungan

KESIMPULAN

maka Nilai Indek Kepuasan Taruna (IKT) setelah dikonversi $=2,843 \times 25=$ 71,065 hal tersebut menunjukkan bahwa mutu pelayanan perpustakaan Sekolah Tinggi Perikanan Jurusan Penyuluhan Perikanan Bogor pada katagori B, dengan kriteria kinerja Baik.

\section{Kesimpulan}

1. Kepuasan taruna terhadap pelayanan perpustakaan rata-rata baik

2. Hanya satu unsur yang dianggap pelayanan sangat baik oleh taruna yaitu tanggung jawab petugas pelayanan

3. Dua unsur pelayanan dianggap kurang baik oleh taruna yaitu unsur 
Kelengkapan buku di perpustakaan dan unsur kesesuaian buku yang ada dengan kebutuhan

\section{Saran}

Perpustakaan perlu meningkatan mutu pelayanan sehingga semua unsur pelayanan pada katagori sangat baik.

\section{DAFTAR PUSTAKA}

Anonimous, 2012. Modul Diklat Pelayanan Publik. Pusdiklat SPIMNAS Bidang Manajemen dan Kebijakan Pembangunan. Lembaga Administrasi Negara.

............, 2012. Peraturan Menteri Pemberdayaan Apartur Negara Dan Reformasi Biriokasi No. 36 tahun 2012. Petunjuk Teknis Penyusunan, penetapan, dan Penerapan Standar Pelayanan. Kemen PAN dan RB RI 2012.

Jansen H. Sinamo, 2004. Etos Kerja Profesional di Era Digital Global. Penerbit Institut Darma Mahardika. Jakarta. 